\title{
Design with Concurrent Approach: Development and Flow Analysis of Injection Mould Tool for Computer Monitor Lamp Holder
}

\section{Prakash $\mathrm{CH}$}

Department of Mechanical Engineering, Adama Science and Technology University, Adama, Ethiopia

\begin{abstract}
\section{INTRODUCTION}

In today's competitive environment, computer aided mould filling simulation packages can accurately predict the fill patterns of any part. This allows for quick simulations of gate placements and helps finding the optimal location (Fine Plastics). Engineers can perform moulding trials on the computer before the part design is completed. Process engineers can systematically predict a design and process to obtain information about the cumulative effect of the process variables that influence the part performance, cost, and appearance (Fine Plastics, Bangalore, India).
\end{abstract}

The plastic product manufacturing industry has been growing rapidly in recent years. One of the most popular processes for making plastic parts is injection moluding. The design of injection mould is critically important to product quality and efficient product processing. Mould-making companies, who wish to maintain the competitive edge, desire to shorten both design and manufacturing leading times by applying a systematic mould design process. The mould industry is an important support industry during the product development process, serving as an important link between the product designer and manufacturer. Product development has changed from the traditional serial process of design, followed by manufacture, to a more organized concurrent process where design and manufacture are considered at a very early stage of design. The research presents the basic structure of two plate injection mould design, injection moulding machine selection, process analysis of the injection mould design using mould flow analysis to optimize the mould cost in the design stage. This injection mould design system covers both the mould design process and mould knowledge management. In this work, $\mathrm{CAE}$ tools have been used in the design stage to reduce the losses to obtain the shortened lead time, high quality and achieving low cost of the mould. The design of an injection process involves the simultaneous consideration of plastic part design, mould design and injection moulding machine selection, production scheduling and cost as early as possible in the design stage. The result indicated that conventional method will consume more time and also increases the cost of machining and delay in dispatching the product. If change in design happens before pre-production and after production by trial and error method then there will be a drastic increase in design change cost which effects on cycle time, waste of raw material, increase in process time and wastage of labour cost. These entire draw backs are eliminated by using computer aided design and computer aided engineering technology for mould design and manufactured in very short period of time with minimum cost. The future scope of work is to include cooling, warpage and fatigue analysis to optimize tool design and tool life. Copyright@2014 STAR Journal. All Rights Reserved.
Article Information

Article History:

Received : 30-01-2014

Revised : 26-03-2014

Accepted : 28-03-2014

Keywords:

Moulding conditions

Plastic injection moulding

Process analysis

Flow Analysis

${ }^{*}$ Corresponding Author:

Prakash C.H

E-mail:

useprakash@gmail.com
The main objective of this work is to design considering concurrent concepts, development and flow analysis of two - cavity injection mould to produce the computer monitor lamp holder. The Poly Butylene Terapthlate (PBT) material is used for the production of this component due to its excellent properties (Dominighaus, 1993).
The process sequence in a conventional method is Product design, Mold Design and Mold process. If any problem occurs in any stage of process then whole cycle has to be repeated on trial and error basis which consume unproductive time, waste of labour, increase in overhead costs, dissatisfaction of customers because of delay in dispatch date and so on. The pictorial view of conventional method is shown in Figure 1.

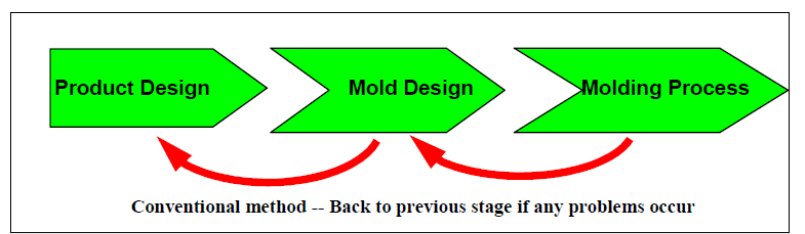

Figure 1: Schematic representation of conventional method of injection moulding process.

Most of small scale industries work on conventional method. Hence the concurrent approach is used to overcome the drawbacks in conventional method. The 


\section{Prakash}

computer aided engineering design of an injection process involves the simultaneous consideration of plastic part design, mould design and injection moulding machine selection, production scheduling and cost as early as possible in the design stage by eliminating all kind of problems with optimal values without any repetition of production cycle resulting reduction in time, minimizing cost, optimal use of labour time and in time dispatch with high quality. The pictorial view of concurrent concept with computer aided engineering method is shown in Figure 2.

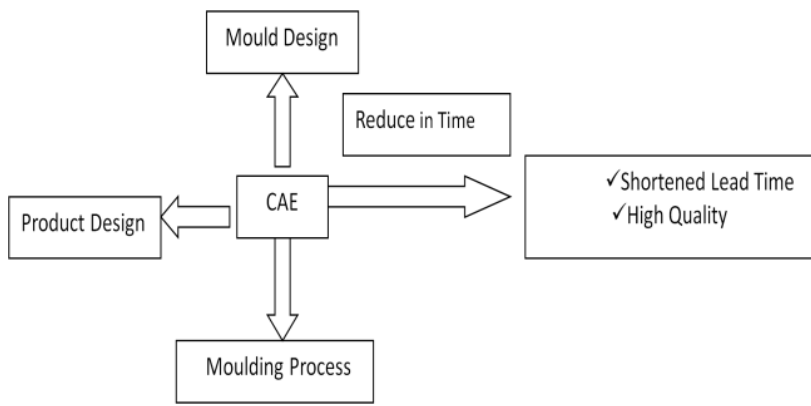

Figure 2: Injection moulding approaches with CAE tools.

In the concurrent concept for plastic injection moulding the tool is designed to produce good quality of the glass fiber enclosure economically. It also facilitates ease of manufacturability to reduce lead time, assembly without compromising quality.

Rong- Shean Lee et al. (1997) discussed the mould design, mould -manufacturing process, mould development parameters for plastic injection mould and the development of a concurrent mould design system. Kwong and Smith (1998) discussed the process design parameters and computer software packages available for flow analysis. Zhai et al. (2006) discussed moldability of a part considering geometric and engineering aspects. Ho et al. (2005) discussed minimizing the manufacturing cost for thin injection moulded plastic components. Li et al. (2006) discussed on in-corporation of commercial CAD/ CAM system to specify the location of each dimension tag. Deng et al. (2006) expressed the use of simulation software and CAD- CAE integration.

\section{MATERIALS AND METHODS}

Polybutylene terephthalate (PBT) is a plastic that is used as an insulator for the electrical and electronics industries. It is a thermoplastic crystalline polymer, and a type of polyester. PBT is resistant to solvents, shrinks very little during forming, is mechanically strong, heatresistant up to $150^{\circ} \mathrm{C}$ (or $200^{\circ} \mathrm{C}$ with glass-fiber reinforcement) and can be treated with flame retardants to make it non-combustible (Dominighaus, 1993).

As a computer aided engineering tool, the mould flow analysis software is used to check the moulding parameters viz. filling time, pressure drop, flow front temperature, weld lines, air traps and shear stress before the tool is manufactured. The tool is designed for highly humid environment as a customer requirement. Three dimensional model (component) of Computer Monitor Lamp Holder is shown in figure 3.

Conventional method of plastic injection moulding is based on the type of artifact, hence the numbers of trials are required to understand like injection time, injection pressure, temperature, clamping force and shear stress. These trials are again required if design is changed.
Sci. Technol. Arts Res. J., Jan-March 2014, 3(1): 136-140

Hence, mould flow simulation analysis used on injection moulding process with input parameters as shown in table 1 to get the quality of the component by making correction in process parameters like injection time, injection pressure, temperature, clamping force and shear stress.

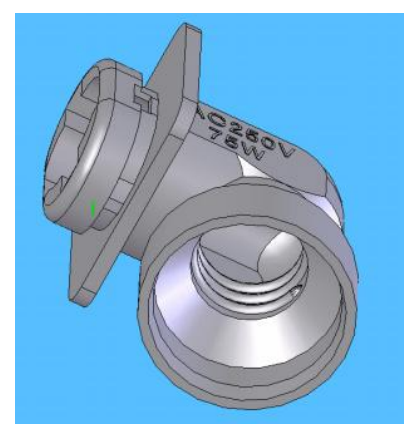

Figure 3: Three dimensional model of computer monitor lamp holder.

\section{Design Calculations}

The tool is designed for SIGMA-150 Injection moulding machine with the following parameters.

\section{Weight of the Component}

Weight of the component (Wc) is given by the equation,

$W c=$ Density $X$ Volume of the component

$W c=1.6 \times 10^{3} \times 6835 \times 10^{-9}=10.936 \times 10^{-3} \mathrm{Kg}$

Plasticizing rate of $\mathrm{PBT}=$ Plasticizing rate of standard plastic $X$ [Total heat of standard plastic/Total heat of PBT]

Plasticizing rate of the material, $\mathrm{Pc}=9.12 \times 10^{-3} \mathrm{Kg} / \mathrm{sec}$

Rated shot capacity of the particular polymer, Ws $=V s \mathrm{X} \rho \mathrm{X} \mathrm{C}$ $W s=130 \times 10^{-6} \times 1.6 \times 10^{3} \times 0.85=0.1768 \mathrm{Kg}$

Tonnage required for the component $=$ Cavity pressure $\mathrm{X}$ Total Projected area

$$
=110.07 \times 75.11 \times 10^{-4}=826735.77 \mathrm{~N}
$$

Diameter of the runner $=D=(\sqrt{ } 10 \times 4 \sqrt{ } 32) / 3.7$

$\mathrm{D}=2.1 \times 10^{-3} \mathrm{~m}$

Width of the gate $=(h X \sqrt{ } A) / 30, A c=52.5 \times 10^{-4} \mathrm{~m}^{2}$

Gate depth, $h g=n g X$ thickness

$\mathrm{hg}=0.8 \times 2=1.6 \times 10^{-3} \mathrm{~m}$

$\mathrm{T}=\rho \times \mathrm{a} \times \mathrm{t}^{2} / 8 \mathrm{Tcp}($ Tmatl - Tmould $)$

$$
T=\frac{1.6 \times 1000 \times 544180 \times 0.002^{2}}{(558-336) \times 0.25116 \times 8}
$$

$\mathrm{T}=7.8 \mathrm{sec}$ Solidifying time $(\mathrm{T})=8 \mathrm{sec}$

Cycle time $=$ Fill time + Solidifying time + Mould opening and closing time + Ejection time + Lubrication time

Cycle time $(\mathrm{Ct})=2.107+8+15+3+8=36.107 \mathrm{sec} \approx 37 \mathrm{sec}$

No. of shots $/ \mathrm{sec}=$ Total time $/$ total cycle time

Cycle time $=0.027$ shots $/ \mathrm{sec}$ (Sanjay K. Nayak et al., 2010)

\section{Heat to be Transferred per Hour by Cooling System}

Weight of the water to be circulated (Mw)

$$
\mathrm{Mw}=\mathrm{Q} 1 / \mathrm{S}[\text { Tout let }- \text { Tin let }] \times \mathrm{K}
$$

Mass of the water to circulated $(\mathrm{Mw})=0.27 \mathrm{~kg} / \mathrm{sec}$ (Pye et al., 1989)

\section{Mould Flow Analysis}

Mould flow analysis is one of the three dimensional solids-based plastics flow simulation software to determine the manufacturability of the part in the early design stages to avoid potential downstream problems which can lead to production delays and cost over runs because of the fact that it will: 


\section{Prakash}

1. Increase the confidence on the design that can be manufactured.

2. Reduce part cost by lowering the amount of material used without compromising quality.

3. Improve part strength and quality with a design that is optimized for the production capabilities and selected material characteristics.

Mould flow simulation analysis in the early design stage itself will avoid the problems like increased cycle time, waste of raw material, process time variation, weld lines and air traps.

The three dimensional computer aided design was imported to mould flow analysis software and process is carried out by feeding input parameters as shown in Table 1.

Table 1: Input Parameters for mould flow analysis

\begin{tabular}{ll} 
Part name & :Computer Monitor lamp holder \\
Material Grade & $: P B T$ with 30\% Glass Fiber \\
Mould Temperature & $: 85^{\circ} \mathrm{C}$ \\
Melt Temperature & $: 280^{\circ} \mathrm{C}$ \\
Maximum Injection Pressure & $: 100 \mathrm{MPa}$ \\
\hline
\end{tabular}

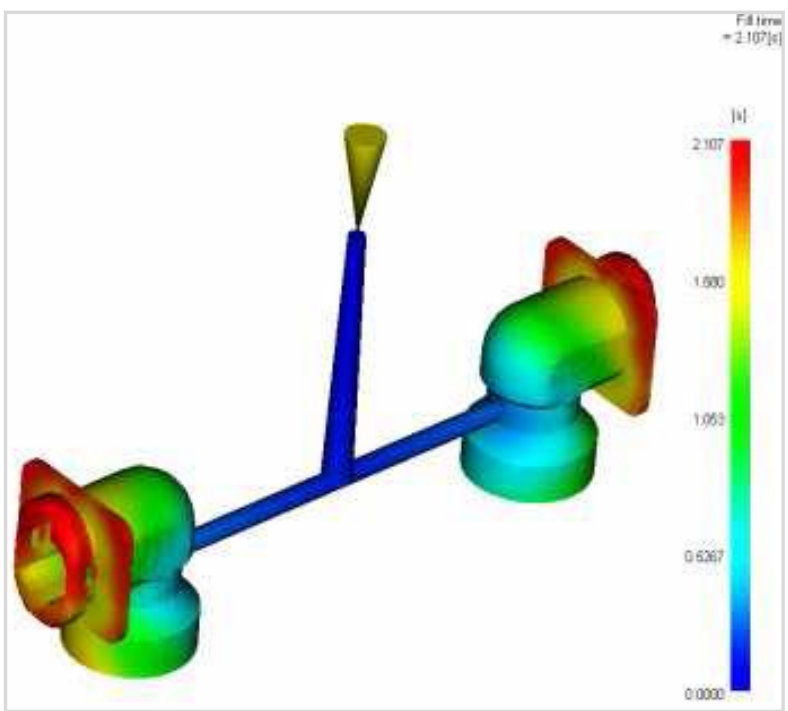

The filling of injection mould tool is $2.107 \mathrm{Sec}$ Figure 4: Injection fill time.

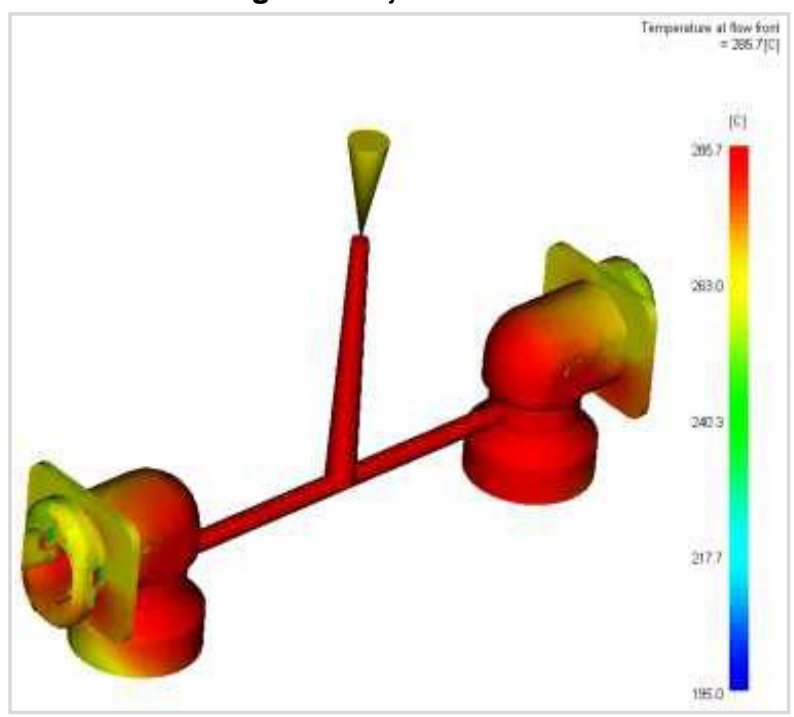

Pressure at velocity pressure switchover is $31.92 \mathrm{MPa}$ Figure 5: Pressure drop.
Sci. Technol. Arts Res. J., Jan-March 2014, 3(1): 136-140

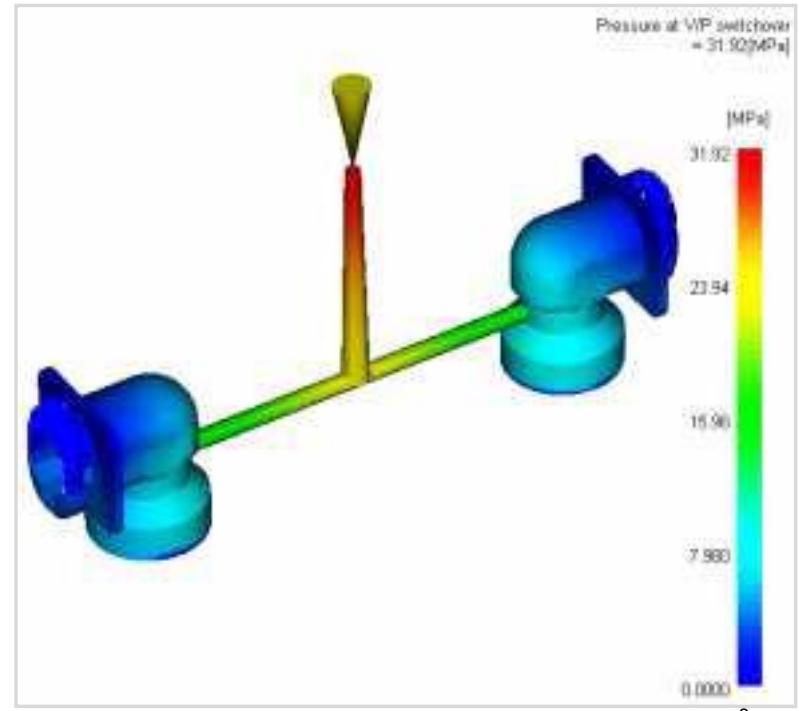

The changes in temperature during filling is $285.7^{\circ} \mathrm{C}$. Figure 6: Flow front temperatures.

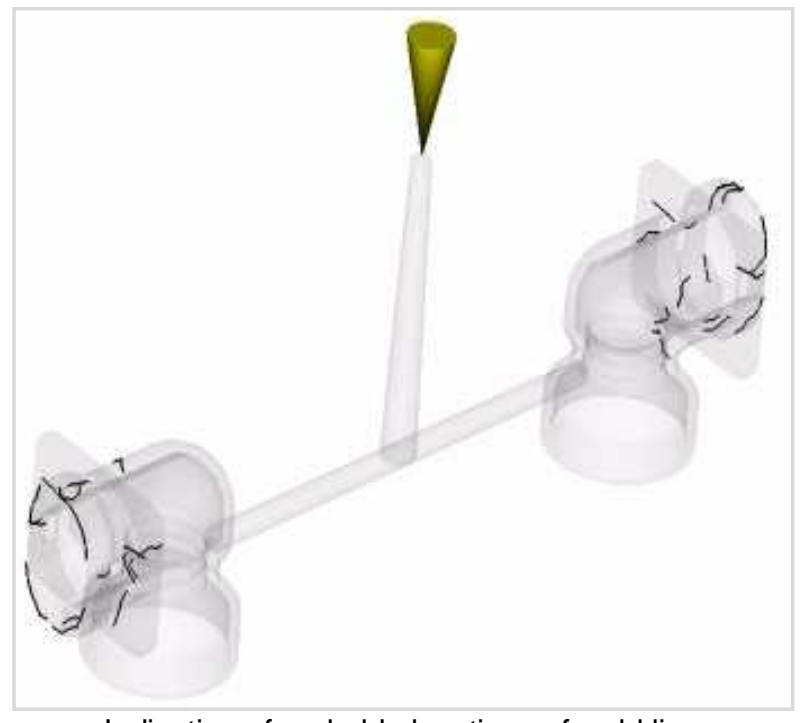

Indication of probable locations of weld lines. Figure 7: Weld lines.

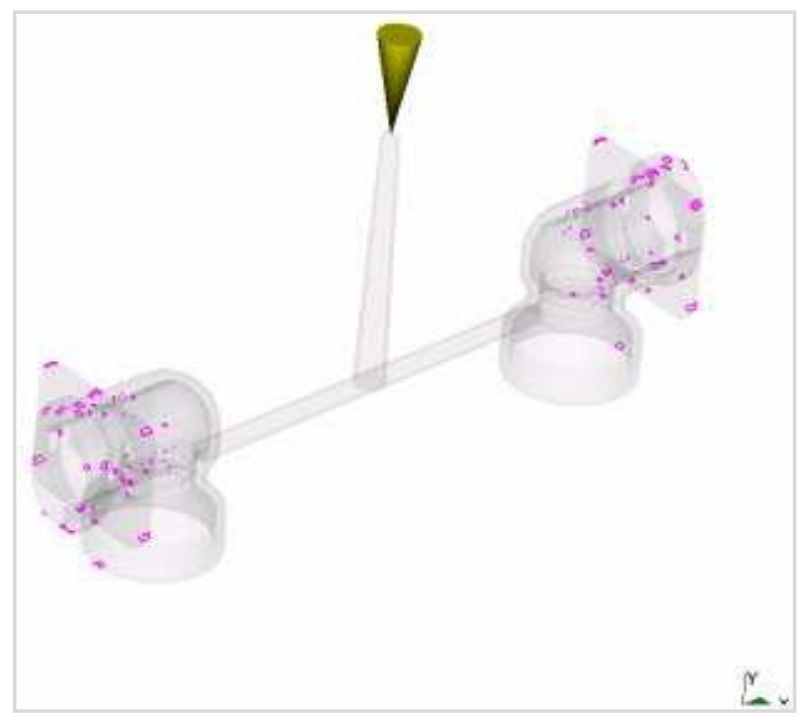

Indication of probable locations of air traps.

Figure 8: Air traps. 
Prakash

The output obtained from mould flow analysis with respect to input parameters is shown in Table 2.

\section{RESULTS AND DISCUSSION}

Different operations for preparation of mould tool for injection moulding are carried out. These operations includes operations on lathe, drilling, milling, grinding,
Sci. Technol. Arts Res. J., Jan-March 2014, 3(1): 136-140

CNC milling, EDM machine like turning, facing, drilling holes, surface milling, finishing operation, grinding operation on flat and cylindrical surfaces. According to industrial standard the number of hours required by conventional and $\mathrm{CAE}$ methods are calculated (Fine Plastics, Bangalore, India) and shown in Table 3.

Table 2: Output from mould flow analysis

\begin{tabular}{ll}
\hline Output Results & \\
\hline Total time taken for filling & 2.107 seconds \\
Pressure at velocity pressure switchover & $31.92 \mathrm{MPa}$ \\
Changes in temperature during filling & Temperature at flow front $285.7^{\circ} \mathrm{C}$ \\
Weld lines and air traps & Probable locations indicated by lines and dots \\
Shear stress at high pressure & Shear stress at wall 0.3 to $0.6 \mathrm{MPa}$ \\
\hline
\end{tabular}

Table 3: Number of hours taken by CAE and conventional method.

\begin{tabular}{lccc}
\hline \multicolumn{1}{c}{ Machining Operations } & $\begin{array}{c}\text { Number of Hours } \\
\text { Required for - CAE }\end{array}$ & $\begin{array}{c}\text { Number of Hours } \\
\text { Required for - Conventional }\end{array}$ & $\begin{array}{c}\text { Difference } \\
\text { of hours }\end{array}$ \\
\hline Lathe & 50 & 70 & 20 \\
Drilling & 80 & 90 & 10 \\
Rough milling & 40 & 40 & 0 \\
Precision milling & 40 & 50 & 10 \\
Surface grinding & 30 & 30 & 0 \\
CNC milling & 50 & 55 & 5 \\
Cylindrical grinding & 30 & 30 & 0 \\
EDM & 70 & 70 & 0 \\
WEDM & 50 & 60 & 10 \\
\hline Total Hours & $\mathbf{4 4 0}$ & $\mathbf{4 9 5}$ & $\mathbf{5 5}$ \\
\hline
\end{tabular}

The number of hours taken by conventional method is 55 hrs more then CAE method as shown in Table 3 . On overall the number of hours of reduction in concurrent CAE approach is $12.5 \%$. The additional operational hours will add additional cost. The increases in operation hour will effects on prolonged dispatch date for customer. All these problems can be eliminated by Computer aided engineering concurrent method. If conventional method is used then marketing department will face difficulty in assuring delivery date to customer, and by using concurrent method exact dispatch date can be assured to the customer.

The Machining Cost is calculated based on number of hours required. Table 4 will show the Machining Cost for CAE Method.
The Machining Cost is calculated based on number of hours required. Table 5 will show the Machining Cost for Conventional Method.

The machining cost of conventional method is USD 200 higher than CAE machining cost shown in Table 4 and Table 5 . Because of increase of machining cost will increase of total cost of product, in turn increases the selling price. Because of high selling price there may be a chance of loosing the order from the customer. All these will overcome by Computer aided engineering method.

\section{Change of Design Cost}

Cost of design changes during part product development cycle is shown in Figure 10

Table 4: Machining cost for CAE method.

\begin{tabular}{lccc}
\hline Machining Operations & $\begin{array}{c}\text { No of Hours } \\
\text { required Values from } \\
\text { Table 1 }\end{array}$ & $\begin{array}{c}\text { Charges per hour } \\
\text { on machines } \\
\text { respectively in USD }\end{array}$ & $\begin{array}{c}\text { Machining cost =No of } \\
\text { Hours } \mathbf{x} \text { Charges per } \\
\text { hour in USD }\end{array}$ \\
\hline Lathe & 50 & 1.33 & 66.67 \\
Drilling & 80 & 0.83 & 66.67 \\
Rough Milling & 40 & 2.50 & 100.00 \\
Precision Milling & 40 & 5.00 & 200.00 \\
Surface Grinding & 30 & 2.50 & 75.00 \\
CNC Milling & 50 & 10.00 & 500.00 \\
Cylindrical Grinding & 30 & 2.50 & 75.00 \\
EDM & 70 & 4.17 & 291.67 \\
WEDM & 50 & 6.67 & 333.33 \\
\hline
\end{tabular}


Table 5: Machining cost for conventional method.

\begin{tabular}{lccc}
\hline Machining Operations & $\begin{array}{c}\text { No of Hours } \\
\text { required (Values } \\
\text { from Table 1) }\end{array}$ & $\begin{array}{c}\text { Charges per hour on } \\
\text { machines } \\
\text { respectively in USD }\end{array}$ & $\begin{array}{c}\text { Machining cost =No of } \\
\text { Hours x Charges per } \\
\text { hour in USD }\end{array}$ \\
\hline Lathe & 70 & 1.33 & 93.33 \\
Drilling & 90 & 0.83 & 75.00 \\
Rough Milling & 40 & 2.50 & 100.00 \\
Precision Milling & 50 & 5.00 & 250.00 \\
Surface Grinding & 30 & 2.50 & 75.00 \\
CNC Milling & 55 & 10.00 & 550.00 \\
Cylindrical Grinding & 30 & 2.50 & 75.00 \\
EDM & 70 & 4.17 & 291.67 \\
WEDM & 60 & 6.67 & 400.00 \\
\hline
\end{tabular}

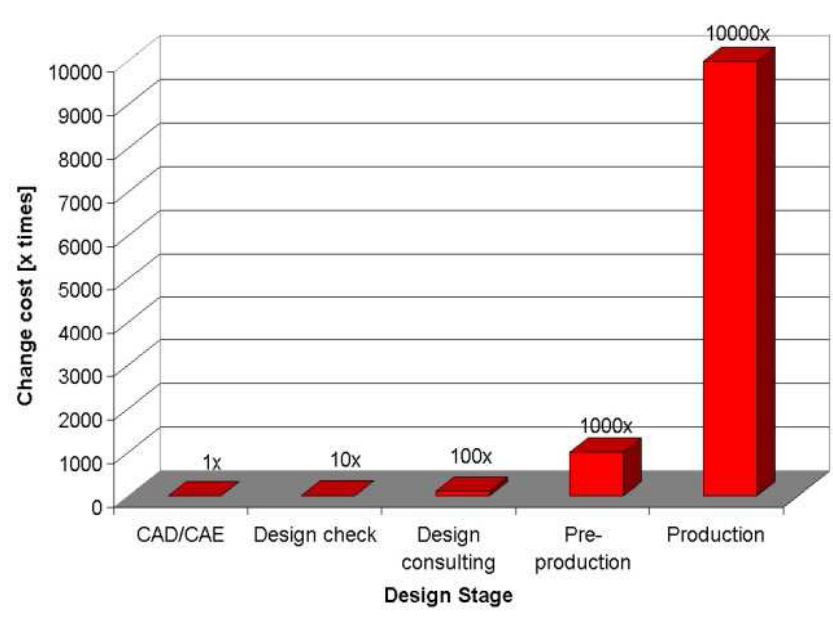

Figure 10: Design change cost.

In conventional method the cost of change in design will have a severe impact on production and total cost as shown in Figure 10. If there are more number of changes in design results more trial and error in design. It observed that 10 fold increase in design check cost, 100 fold increases in design consulting and 1000 fold increase in pre production cost. Due to trial and error approach the production cost will shoot to 10000 times in conventional method. The trial and error method will increase the cycle time, waste of raw material and un-productive activities. All these drawbacks can be minimized by using CAE concurrent approach with mould flow analysis simulation software.

\section{CONCLUSIONS}

In the plastic injection moulding, the CAD model of the plastic part obtained from commercial three dimensional programs could be used for the part performance and injection process analyses. With the aid of $\mathrm{CAE}$ technology and the use of knowledge management, not only the injection mould can be designed and manufactured in a very short period of time with a minimized cost but also all potential problems which may arise from part design, mould design and processing parameters could be eliminated at the very beginning of the mould design. This tool helps to develop a good product with a better delivery and faster tooling with less time and money.
The Mould flow analysis can further be used to carry out cooling and warpage analysis. The results can be used for, further optimization of the tool design. Fatigue analysis can be carried out for the tool, which results in providing information of the life of the tool.

\section{REFERENCES}

Banga T.R., Sharma, S.C. (2003). Mechanical Estimating and Costing. Khanna Publishers, New Delhi, India.

Deng, Y.M., Britton, G.A., Lam. Y.C. (2006). Towards automatic a shape modification in injection mouldedplastic -part design. The International Journal of Advanced Manufacturing Technology 28(5-6): 495-503.

Dominighaus, H. (1993). Plastics for engineers. Hanser Publisher, Munich, Vienna, New York, Barcelona.

Fine Plastics, No 53/1, Tulsinath Industrial Compound, 4 th main road, $3^{\text {rd }}$ Phase, Peenya, Bangalore -560058 .

Ho, J.K.L., Chu, K.F., Mok, C.K. (2005). Minimizing manufacturing costs for thin injection molded plastic components. The International Journal of Advanced Manufacturing Technology 26(5-6): 517-526.

Kwong, C.K. and Smith. G.F. (1998). A Computational System for Process Design of Injection Molding: Combining a Blackboard-Based Expert System and a Case- Based Reasoning Approach. The International Journal of Advanced Manufacturing Technology 14(4): 239-246.

Li, C.L., Yu, K.M., Lee. Y.H. (2006). Automatic datum dimensioning for plastic injection mold design and manufacturing. International Journal of Advanced Manufacturing Technology 28(3-4): 370-378.

Pye, R.G.W., Ronald George William Pye. (1989). Injection Mould Design. Longman Publishers.

Rong-Shean Lee, Yuh-Min Chan and Chang-Zou Lee. (1997). Development of a concurrent mould design system: a knowledge -based approach. Computer Integrated Manufacturing Systems 10(4): 287-307.

Sanjay K. Nayak., Kuppuswamy, A., Rao, A.K. (2010). Plastics Mould Technology. Volume I and II, CIPET Publishers, Guindy, Chennai.

Zhai, M. Lam, Y.C. Au. C. K. (2006). Runner sizing and weld line positioning for plastics injection molding with multiple gates. Engineering with Computers 21(3): 218-224. 